\section{La discapacidad en relación con la educación, \\ la justicia social y la calidad de vida}

Disability related to

education, social justice, and quality of life

\section{A discapacidade relacionada à educação, à justiça social e à qualidade de vida}

\section{Nahir Rodríguez de Salazar*}

* Profesora y doctoranda en Educación, Universidad Pedagógica Nacional, Bogotá, Colombia.

Correo electrónico: nahirs@pedagogica.edu.co

\section{Resumen}

La experiencia de incluir a la educación personas con discapacidad, en especial al sistema universitario, revela un proceso bastante complejo producto de una serie de factores que, de una u otra forma, evidencian la ausencia de pensamiento, políticas y estructuras sociales dispuestas para favorecer el pleno desarrollo humano y la calidad de vida de los miembros de la sociedad. Este artículo presenta algunas ideas objeto de análisis, debate y reflexión que permita, desde otras aristas, considerar la complejidad de los procesos de inclusión y los factores que condicionan la posibilidad de vivir una vida digna y con justicia social.

\section{Palabras claves}

Discapacidad, inclusión, calidad de vida, justicia social, desarrollo humano.

\section{Abstract}

Experience of inclusion of people with disability in education, specially to the higher education system, shows a quite complex process which is the result of a series of factors that, in one way or another, bears witness to the lack of thought, policies, and social structures, prepared to help complete human development and the quality of life of all of the members of the society.

This document shows some ideas to analyze, debate, and think about them, which allow us to consider the complexity of inclusion processes and the factors that determine the possibility of living an honorable life with social justice.

\section{Key words}

Disability, inclusion, quality of life, social justice, Human development.

\section{Resumo}

A experiência de incluir na educação pessoas com discapacidade, particularmente no sistema universitário, é um processo complexo resultante de uma série de fatores demonstrarem a ausência de pensamento, políticas e estruturas sociais organizadas para promover o pleno desenvolvimento humano e a qualidade de vida dos membros da sociedade.

Este artigo apresenta algumas idéias para reflexão, análise e a fim de considerar a complexidade dos processos de inclusão e os fatores que determinam a possibilidade de viver com dignidade e justiça social.

\section{Palavras-chave}

Discapacidade, inclusão, qualidade de vida, justiça social, desenvolvimento humano.

Fecha de recepción: 30 de marzo de 2010 Fecha de aprobación: 15 de Junio de 2010 
vas respecto de sus capacidades... Todo contribuye, en fin, a mantener el estado de cosas, sin permitir las transformaciones deseadas dentro de las visiones optimistas que han caracterizado la educación, especialmente en los últimos tiempos. Es decir, en las sociedades contemporáneas no ha sido posible avanzar en la apuesta planteada por Vigotski (1995) en relación con la importancia de educar e integrar socialmente al niño con deficiencia, para que pueda constituirse en un ciudadano útil y plenamente ajustado a las exigencias de la sociedad.

En medio de este panorama, que puede parecer un tanto desalentador, emergen diversos interrogantes. Por ahora atenderemos a uno en particular: ¿de qué manera un enfoque centrado en desarrollo a escala humana y calidad de vida posibilita un cambio de paradigma en la atención de personas con discapacidad? Al respecto, una mirada restrospectiva acerca de la forma como ha sido atendida históricamente la discapacidad será pretexto para reflexionar en cuando al sentido de la inclusión como visión dignificante del hombre con discapacidad.

Castel (1975) en su reflexión acerca de la génesis y las ambigüedades de la noción del sector de la psiquiatría plantea un interrogante: ¿cuál es el nuevo dispositivo global que ocupa progresivamente el lugar de encierro manicomial, con qué objetivo y en interés de quién? Este cuestionamiento, de pertinencia no solo en la psiquiatría sino también en la educación de personas con discapacidad, se convierte en una excelente invitación para intentar comprender aquellas intencionalidades que subyacen en los planteamientos de distintas corrientes que, a través de la historia, han orientado la atención de los llamados discapacitados, objeto de tratamiento educativo o rehabilitatorio.

Aparentemente, para la sociedad, la atención de la discapacidad se constituye en cuestión de filantropía. Esta mirada, de una u otra forma, ha tenido mucha influencia en el tipo de tratamiento que se brinda a las personas con discapacidad en las distintas culturas. La ausencia de una teoría social de la discapacidad, planteada por autores como Barton (1988) o Franklin (1996) contribuye a mantener las visiones lastimeras, proteccionistas y caritativas que, junto a visiones religiosas, perpetúan imaginarios y representaciones sociales.

Sin embargo, para los grupos de poder y control social, la discapacidad, en el terreno de lo público, representa amenaza para la estabilidad de la sociedad y de los miembros que la constituyen. Lazerson (1975) hace una interesante reflexión en torno a la forma como ha evolucionado, en Estados Unidos, la educación especial. Al analizar discursos de administradores escolares como Whitney, M. (1896), Ettinger, L. (1920) y Landrum, L. (1916) descubre que allí aparece una intencionalidad común: evitar el excesivo gasto que los discapacitados causan al Estado. Así, la atención educativa de la discapacidad se orienta por criterios situados más en la perspectiva financiera que en la humanitaria y de conocimiento científico.

La educación especial, lejos de tener una pretensión académica, social y cultural, emerge en sus inicios como una necesidad de controlar, por una parte, la economía y, por otra, de prevenir la amenaza que representan, para una sociedad, los categorizados o rotulados como discapacitados. Las palabras de Pearse (citado en Franklin, 2006, p.8) sirven para ilustrar la forma como se pensaba acerca de la educación, en clases segregadas de los alumnos especiales pues: “...le evitarían al Estado el daño que estos niños pudieran causar en las escuelas".

Un fenómeno similar sucede en los orígenes de la educación especial en Francia. Los planteamientos de Muel, F. (1991), a propósito de su artículo "La escuela obligatoria y la invención social de la infancia anormal", revelan la tensión existente entre el humanitarismo y el control social de la discapacidad, es decir, a la comprensión científica de esta se impone el interés económico y político, planteado también en la misma época, en Estados Unidos.

En sus hallazgos, Muel hace afirmaciones que reflejan cierta coincidencia con las intencionalidades encontradas por Lazerson: "Se fabricarán de los no-valores sociales, con frecuencia enojosos, seres capaces de entrar en la vida de los normales o, al menos, entidades capaces de proporcionar un trabajo útil y de disminuir así sus gastos de mantenimiento." Así, la institución educativa, más que pensar en el desarrollo humano integral de estos

“La educación especial, lejos de tener una pretensión académica, social y cultural, emerge en sus inicios como una necesidad de controlar, por una parte, la economía y, por otra, de prevenir la amenaza que representan, para una sociedad, los categorizados o rotulados como discapacitados." 
sujetos, se ve implicada en lo que Muel (1991) señala como "órganos del deber social". La clase política y las élites privilegiadas crearán los mecanismos necesarios que garanticen su seguridad. Si bien en Francia se configuran campos como el médicopedagógico y el psiquiátrico, ellos también son, en cierta medida, subsumidos por fuerzas del poder político, económico y social, en tanto la prevalencia del saber teórico y académico de la psiquiatría, por ejemplo, queda inscrita en el aparato del Estado y como un saber con mayores grados de legitimidad para generar tecnologías que, aplicadas a seres anormales, promuevan el disciplinamiento $y$, con él, la disminución del peligro que representan para el cuerpo social. Este saber, como muchos otros, no es totalmente autónomo porque entra a depender de la producción y del comercio, tal como lo plante Engels (Muel, 1991, p. 125).

La legitimidad, desde la perspectiva de Estado planteada por Bourdieu, consiste en el moldeamiento de las estructuras mentales para que entren en correspondencia con las estructuras sociales. Así, el conocimiento que se configura desde los campos médico y pedagógico no será independiente puesto que entra en directa correlación con los juegos de poder del que se derivarán estrategias que permiten el control de los rotulados como "anormales", cuyos comportamiento demanda, a través de sistemas de clasificación, medición e intervención, espacios de reclusión y aislamiento en previsión de los daños que pueden causar a la sociedad. Para Bourdieu, esta orientación de la educación de los anormales, centrada en el aislamiento con propósitos de normalización de los sujetos; denota el ejercicio de la violencia simbólica por parte del Estado sobre un territorio determinado y el conjunto de la población.

Los estudios de Kivirauma y Kivinen (citado en Barry, 1996) señalan la función de control social que ha cumplido la educación especial, de acuerdo con los distintos momentos históricos. Por ejemplo, con el proceso de industrialización, la escuela especial debía albergar al sector de la población que no se ajustaba al ideal requerido por las escuelas regulares, establecidas con el propósito de preparar hombres que pudieran aportar fuerza de trabajo al sector productivo.

De esa manera, la escuela regular excluye y conduce al encierro, a través de los centros especiales, a los niños cuyo rendimiento escolar, su temperamento o sus rasgos físicos no encajaban con los perfiles del hombre predeterminado por los Estados para responder a los fines económicos. En otras palabras, la escuela especial entra a ser parte de lo que Foucault denomina "encierro"; "fruto del afán burgués de poner en orden el mundo de la miseria" (Pérez, 1998, p. 24). Este encierro, enmarcado dentro del disciplinamiento, se caracterizará, hablando en términos de Foucault, por el ejercicio del poder, el aislamiento, la violencia, el sometimiento y el sufrimiento, prácticas que aún se mantienen en algunos centros educativos que atienden la discapacidad, y en hospitales psiquiátricos, debido a que se impone el poder político sobre el saber del médico y del pedagogo, tal como plantean Castel (1991) y Muel (1991).

No debe olvidarse, en nuestro medio colombiano, qué ha significado la "hospitalización" de los pacientes rotulados como psiquiátricos y de los niños "enfermos;; es decir, los "retrasados mentales" dispuestos en asilos del sector público. Allí han sido confinados a todas las formas de maltrato que, hasta hace no más de veinte años, recreaban prácticas indignas -choques eléctricos, castigos en cuartos oscuros- justificadas por la escasa inversión del Estado en la población interna, objeto de doble abandono: familiar y estatal.

Hunt (citad en Barton, 1998), al plantear la discapacidad en el terreno de lo social, resalta las implicaciones discriminatorias y opresivas que ella genera en sociedades que, por patrones culturales, consideran su escaso potencial para el trabajo y el disfrute de los beneficios materiales de las sociedades modernas. Al volcarse la prioridad social sobre la producción, en tanto bien económico, se justificará el trato inhumano dado en sanatorios y centros especiales, debido a su inutilidad para producir económicamente.

Este encierro, producto del tránsito de una sociedad feudal a una sociedad industrializada que excluye del mundo laboral a las personas que no están en capacidad de competir con las exigencias impuestas por las fábricas, ahondará la brecha existente entre los discapacitados y la sociedad, debido a que el mercado pasa a ser el elemento fundamental y la educación se sitúa en el plano de la inversión y rentabilidad económica. Finkelstein y Barnes (citado en Barton, 1998).

Para algunos investigadores de orientación materialista, el estado de opresión o abandono de los discapacitados tiene explicación desde las estructuras económicas; de este modo se plantea que el fenómeno de la discapacidad debe ser analizado más allá de lo netamente individual. Situar la discapacidad en el terreno de lo social implica estudiar, además de la opresión, otros aspectos fundamen-

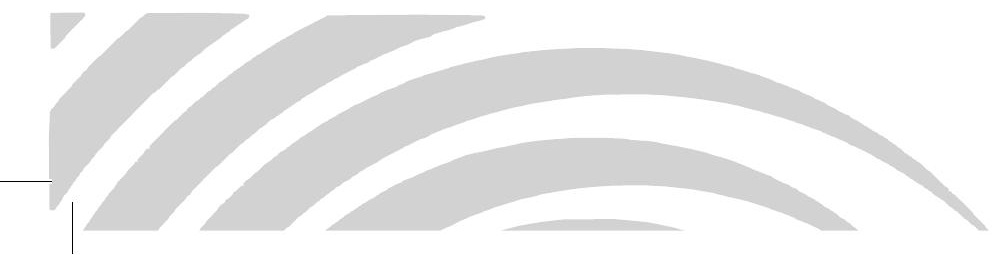


tales y complejos. Por ejemplo, Abberley (citado en Barton, 1998) analiza la posición de inferioridad de los discapacitados frente a otros miembros de la sociedad; grandes desventajas que se nutren de las ideologías que sobre ellos se construyen y que ayudan a mantener y perpetuar el fenómeno de la discapacidad, y sugiere cómo la discapacidad, en la perspectiva materialista, debe ser comprendida como resultado del fracaso de la sociedad para adaptarse a las necesidades de estas personas.

En esa misma visión, Hunt (citado en Barton, 1998) analiza el gran valor que la cultura occidental otorga al trabajo y las graves dificultades de las personas con insuficiencias o discapacitadas para contribuir en el bienestar económico de la sociedad. Así, los discapacitados entran en choque con los valores sociales aceptados y compartidos por todos los miembros que la constituyen; Oliver (citado en Barton, 1998) destaca que la categoría "discapacidad" deriva como producto de las relaciones economía-organización social del trabajo, donde los miembros que la conforman no pueden, por sus insuficiencias, ingresar en el mundo de la competitividad, con lo cual se producen fenómenos de exclusión, marginación social y minusvalía.

Finkelstein (citado en Barton, 1980) sostiene que la discapacidad, entendida como incapacidad de adaptación a las exigencias del mundo laboral, tiene su origen a partir del desarrollo de la sociedad industrial occidental; es decir, ella no surge en el período feudal, sino en la fase de afianzamiento de la industrialización, siglo XIX, cuando debieron excluir del mundo laboral a quienes no podían seguir el ritmo de trabajo que se imponía en las fábricas; entonces, se les confinó a los encierros y, de manera indigna, se les separó de los procesos de interacción con la sociedad.

Situada la discapacidad como una problemática social que amenaza la estabilidad de los Estados, resulta romántico pensar la educación especial como resultado de las buenas prácticas y las acciones humanitarias, o las inclinaciones optimistas propias de humanistas que, en términos de Lazarson (citado en Franklin, 1996, p. 8), no han logrado hacer una lectura en el marco de los acontecimientos políticos, económicos y culturales de las sociedades capitalistas. A su juicio, la tensión entre humanitarismo y control social caracterizará la educación especial del siglo XX.

La visión humanista está siempre cediendo ante las políticas centradas en el favorecimiento de lo económico y el poder del Estado para controlar un sector que, a pesar del paso de la historia, continúa representando peligro no solo por el gasto econó- mico que causa sino por la forma como pueden desestabilizar el trabajo académico en los centros escolares e impactar negativamente en el sector social. De este modo, la exclusión del sistema educativo mediante formas de segregación, que aún hoy existen, se impulsó como opción para proteger las clases dominantes de seres defectuosos y problemáticos que han puesto en peligro el orden social existente. Se ha partido de la creencia que los discapacitados pueden provocar caos, desorden social y delincuencia, por lo que se hace necesario el control sobre su comportamiento, a través de distintas estrategias que van desde el encierro en manicomios hasta la segregación en aulas especiales. Franklin (1996, p. 30) cuestiona la benevolencia inmersa en la educación especial al analizar las complejidades $\mathrm{y}$ las contradicciones que yacen en un movimiento estatal dirigido hacia la regulación social.

No en vano se considera que la discapacidad queda anclada a la pobreza, al fenómeno de la inmigración y al desplazamiento. Hoy, por ejemplo, en nuestro país ${ }^{6}$, los discapacitados constituyen parte de las llamadas poblaciones vulnerables y, tal como sucedió en Francia o Estados Unidos, siguen representando una amenaza para la sociedad y para el Estado. Desde tales condiciones y concepciones, se generan dispositivos de control social que esconden ciertas intencionalidades, como las políticas de integración o de inclusión que, si bien han creado ilusión, no han logrado las transformaciones esperadas por los humanistas, los maestros y las familias, en tanto obedecen a procesos fijados por la dinámica del actual capitalismo que ha confiado, a organismos internacionales de crédito, ciertas funciones y atribuciones, sin tomar en cuenta la dinámica propia de la realidad cultural, educativa y social del país.

Si bien no pueden desconocerse propuestas de integración e inclusión con enfoque humanista, interesadas en el desarrollo pleno del hombre, en sus derechos y la importancia de llevar una vida digna, su florecimiento es muy lento porque en el ámbito mundial prima la visión económica y utilitarista sobre la humanística y filosófica. Las reflexiones de Nussbaum (2007) alrededor de la situación de las personas con discapacidad abren un interesante pa-

6 Compromiso nacional pactado en foros internacionales y conferencias mundiales -Salamanca, España: 1994; Senegal, Dakar: 2000- donde se reafirma el compromiso y la urgencia de impartir enseñanza a todos los niños, jóvenes y adultos con necesidades educativas especiales, dentro del sistema común de educación. También en Senegal, Dakar.2000, donde las naciones se comprometen a cumplir con los objetivos y metas de la educación para todos... para todos los ciudadanos y todas las sociedades. 
norama para pensar los procesos de inclusión. Allí se plantea que "la incapacidad de dar respuesta adecuada a las necesidades de los ciudadanos con deficiencias y discapacidades es un grave defecto en las teorías modernas, que derivan los principios políticos básicos de un contrato para el beneficio mutuo". Desde esta visión, las sociedades justas deben avanzar hacia la no estigmatización de los discapacitados, a través de la garantía de educación, salud y condiciones para la plena participación social y política, sin que medie la retribución que se espera como parte del compromiso social de los ciudadanos.

Del mismo modo, Nussbaum señala la importancia de considerar a cada persona como un fin, y no como un medio, y la importancia de tomar en cuenta los derechos básicos, el reconocimiento de la dignidad de todo ser humano y el derecho de llevar una vida acorde con esa dignidad, porque, hablar de la justicia social implica "extender la justicia a todos los ciudadanos del mundo y desarrollar un modelo teórico de un mundo justo donde los accidentes de nacimiento no vicien, desde el principio y en todos los sentidos, las opciones vitales de las personas".

Por su parte, Amartya Sen (1998), desde sus planteamientos de filosofía política y moral, aporta al debate de la inclusión de los discapacitados con su referencia al desarrollo como "proceso de expansión de las libertades reales que disfrutan todos los individuos de un país". En sus postulados concede prioridad tanto a los derechos políticos y humanos como a las realidades que repercuten en el diario vivir de cada hombre. Su invitación consiste en eliminar todo tipo de restricciones que impidan el disfrute de las libertades humanas, bien por razones de pobreza o ausencia de los servicios sociales que el hombre requiere para desarrollarse en las dimensiones social, política y económica.

Las anteriores tendencias encierran principios y orientaciones esenciales para llevar a cabo procesos de inclusión, en la escuela y la sociedad, de personas con discapacidad; sin embargo, su puesta en desarrollo es compleja porque el mundo continúa rigiéndose, con desafuero, por una economía de mercado donde el bienestar y el desarrollo humanos carecen de importancia frente a la presión de corrientes centradas en la producción y el crecimiento económico. En ese desmedido afán por la concentración de riqueza y poder, las grandes transnacionales influyen sobre los Estados-nación, que continúan sometidos a condiciones de explotación, pobreza y violación de los derechos fundamentales de su población, especialmente en regiones del mundo catalogadas "subdesarrolladas" o "países emergentes". Así las cosas, para la población con disca- pacidad, que no representa una fuerza productiva, será muy lento alcanzar su verdadero estatus, dada la perpetuidad de la injusticia social, con lo cual su calidad de vida empeora debido a la imposibilidad de satisfacer sus necesidades básicas. A pesar de ello, emergen propuestas, como la de Max Neef, que señalan la necesidad de anteponer al interés económico, el derecho a la vida y a la libertad de "todas las personas".

\section{"Vale la pena poner en cuestión los procesos de integración e inclusión} que, aunque ocupan las agendas de los ministerios de educación y salud de los distintos países, todavía no han logrado impactar favorablemente en la sociedad"

Vale la pena poner en cuestión los procesos de integración e inclusión que, aunque ocupan las agendas de los ministerios de educación y salud de los distintos países, todavía no han logrado impactar favorablemente en la sociedad y, menos, garantizar las capacidades básicas para que los ciudadanos funcionen de un modo auténticamente humano y logren la dignidad que merece todo ser: vida, salud física, integridad física, sentidos, imaginación y pensamiento, emociones, razón práctica, afiliación, relación con otras especies, juego y control sobre el propio entorno (Cfr. Nussbaum, 2000, pp. 88-89).

En este sentido, ha de decirse, aunque suene casuístico, que diariamente las familias se enfrentan con procesos de exclusión de niños, jóvenes y adultos que no pueden acceder al mismo sistema de educación especial, en razón de que los diagnósticos y las mediciones e indicadores no posibilitan su interacción con el ámbito escolar. La educación especial también continúa estigmatizando y los maestros, formados por el sistema, dicen no tener la suficiente experiencia y conocimiento para tratarles. Teoría y práctica en este campo resultan totalmente contradictorias, mientras la calidad de vida del discapacitado y los pobres continúa ausente de las condiciones mínimas necesarias para sobrevivir como seres con derechos.

La situación de la discapacidad se ha agudizado con el paso del tiempo, al menos para los países en desarrollo, o "emergentes"7. El mismo Banco

\footnotetext{
7 Término eufemístico con el cual se quiere desdibujar la situación de miseria que viven las poblaciones de los países pobres.
}

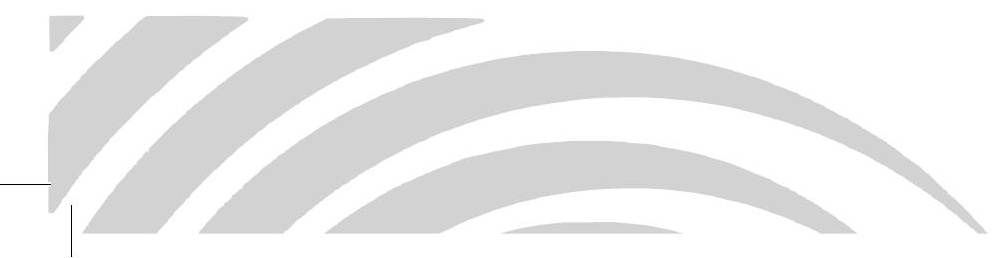


Mundial da cuenta del elevado índice -10\%- de población con discapacidad que, en pleno siglo XXI, vive en condiciones extremas de pobreza y es excluida, aun por sus propias comunidades, porque no son seres productivos.

Si bien el Banco Mundial plantea la importancia de adoptar políticas que satisfagan las inquietudes y las necesidades de desarrollo de las personas con discapacidad, el análisis, desde la investigación sociológica, de las razones expuestas por este organismo de atender la discapacidad, puede comprenderse como una estrategia más para prevenir el inminente peligro que corren los países industrializados con el aumento desmedido de la pobreza.

Corbalán (2002) hace un singular análisis del sentido implícito en los planteamientos de Robert McNamara, hacia la década del 60, quien, alejado de posturas éticas, remarcaba la importancia de atender el fenómeno de la pobreza como mecanismo para evitar colapsos en las relaciones económicas entre los países desarrollados y los "tercermundistas".

El Banco Mundial y el Fondo Monetario Internacional contemplan, en sus planes y proyectos actuales, la discapacidad como tema prioritario en sus procesos estratégicos de lucha contra la pobreza, por considerar que tanto discapacidad como pobreza conforman un binomio singularmente peligroso, pero las propuestas siguen enmarcadas en su propia misión: consolidación del poder de las grandes potencias, a través de técnicas y estrategias de disciplinamiento y gestión, aparentemente humanitaria, porque, en el fondo, los proyectos y los programas de atención a la discapacidad están orientados a aliviar los empréstitos que tienen los países pobres con la banca internacional.

En otros términos, lejos de una visión humanitaria y de justicia social, se promueven acciones prácticas despojadas de la realidad de los contextos y de las creencias y costumbres que caracterizan cada cultura. Proyectos como el de la educación

"La inclusión, en el campo de la vida social, implica fuertes cambios en las representaciones sociales, las transformaciones culturales y la preparación de la escuela y los formadores, y no puede quedar reducida a moda, eufemismo, a concepto vacío." inclusiva son asimilados, de manera acrítica, por instituciones rectoras, profesores y demás académicos. Hoy, por ejemplo, se cuestiona, en Colombia, que haya dejado la experiencia de la integración de personas con discapacidad, en los sujetos y en la sociedad y sus familias. Aún no es claro qué sucedió. A pesar de ello, la educación se enruta por la inclusión, sin haber generado procesos de reflexión, formación y organización. Distintas técnicas de disciplinamiento, como la persuasión, la formación de cuadros técnicos, pasantías externas con fines de entrenamiento, programas focalizados, asistencia técnica internacional, cursillos de formación específica, entre otras, han sido impulsadas, desde el Ministerio de Educación, en respuesta a políticas externas de globalización.

Aunque esas formas y estrategias varían para poder mantener la cordialidad entre los países, sobre el desarrollo del hombre prima el desmedido e inequitativo interés económico. Es usual que los sistemas nacionales pauten irreflexivamente políticas y proyectos internacionales que no conducen más que a frustración y cambios cíclicos.

A propósito de la apuesta educativa y social de la inclusión, se pone en tela de juicio el resultado de las políticas de integración escolar que no lograron colmar, en los últimos diez años, las expectativas que habían generado sobre el acceso a la educación de todos, incluidos los discapacitados. Tiene, entonces, pertinencia el llamado de Corbalán (2002, p. 189) en relación con la necesidad comprender, en profundidad, los indicios y los presupuestos que subyacen a las propuestas y proyectos señalados por agencias internacionales. El tema de la discapacidad debe resistir los análisis desde distintas perspectivas interdisciplinares, donde las teorías críticosociales hacen un invaluable aporte, pues la discapacidad forma parte de la problemática económica, social y cultural, y no puede perpetuarse su anclaje a la visión médica y pedagógica.

La inclusión, en el campo de la vida social, implica fuertes cambios en las representaciones sociales, las transformaciones culturales y la preparación de la escuela y los formadores, y no puede quedar reducida a moda, eufemismo, a concepto vacío. Sin embargo, para el caso colombiano, pareciera correr la misma suerte de la integración, debido a la ausencia de un discurso que, situado en una realidad compleja, permita configurar, con el aporte disciplinar de las ciencias sociales, un conocimiento propio que oriente las acciones y las prácticas pedagógicas. Por el momento, el concepto ha sido asumido por todos, incluso por quienes ven en ella formas de evasión del alto costo que tiene la formación de 
los discapacitados. Pero esto significa estudiar en profundidad el verdadero interés y papel que tienen los organismos de poder al impulsar, de manera irrestricta, en los distintos países en desarrollo, políticas y lineamientos a favor de la inclusión. ¿Acaso no es una estrategia más de disciplinamiento, control social e interés monetario? $\mathrm{O}_{i \text { Es }}$ una estrategia más, en el marco de la cooperación internacional, para lograr, con los distintos Estados, cambios estructurales en beneficio de las políticas de globalización?

\section{Bibliografía}

Agamben, G. (2006), Homo sacer. El poder soberano y la nuda vida, Valencia, Pretext.

Bartón, L. (1998), Discapacidad y sociedad, Madrid, Morata.

Castel, R. (1975), “Génesis y ambigüedades de la noción del sector en psiquiatría”, en: Espacios de poder, Madrid, La Piqueta, pp. 143-175.

Corbalán, A. (2002), El Banco Mundial. Intervención y disciplinamiento, Buenos Aires, Biblos.

Egler Montoan, M. (2003), Inclusao escolar, Sao Paulo, Moderna.

Franklin, B. (1996), Interpretación de la discapacidad. Teoría e historia de la educación especial, Barcelona, Pomares.

Max-Neef, M. (1996), Desarrollo a escala humana, Upsala, Suecia, CEPAUR. Centro de Alternativas de Desarrollo Fundación Dag Hammarskjöld.
Por el momento, e invocando acciones humanitarias, la discapacidad ha sido objeto de aberraciones como las planteadas por Agamben (2006, p. 172-181), a propósito del programa de eutanasia elaborado y ejecutado por Hitler en los campo de concentración de Nüremberg: "la eliminación de la vida indigna de ser vivida". Ello ejemplifica, una vez más, la forma como el hombre, al igual que las instituciones con poder, regula la vida de los otros: la de los pobres y los discapacitados.

Nussbaum, M. (2007), Las fronteras de la justicia. Consideraciones sobre la exclusión. Barcelona, Paidós.

Nussbaum, M. y Sen, A. (1998), La calidad de vida, México, Fondo de Cultura Económica.

Muel, F. (1975), "La escuela obligatoria y la invención de la infancia anormal", en Espacios de poder, Madrid, La Piqueta, pp. 123-142.

Pérez, N. (1998), La capacidad de ser sujeto. Más allá de las técnicas en Educación Especial, Barcelona, Laertes.

Unesco (1994), Declaración de Salamanca y marco de acción ante las necesidades educativas especiales, París.

(2000), Foro mundial sobre la educación. Marco de acción de Dakar, París.

Varela, J. y Álvarez, F. (1991), Espacios de Poder, Madrid, La piqueta. 